\title{
Identification and sequencing of the groE operon and flanking genes of Lawsonia intracellularis: use in phylogeny
}

\author{
C. Jane H. Dale, ${ }^{1,2}$ Eric K. Moses, ${ }^{1}+$ Chin-Chui Ong, ${ }^{1,2}$ Chris J. Morrow, ${ }^{1}$ \\ Michael B. Reed, ${ }^{1,2}$ Dete Hasse ${ }^{1}$ and Richard A. Strugnell ${ }^{2}$
}

Author for correspondence: Richard Strugnell. Tel: +6139344 5712 Fax: +61393471540.

e-mail: Richard_Strugnell@muwayf.unimelb.edu.au

1 Victorian Institute of Animal Science, 475 Mickleham Road, Attwood, Victoria 3049, Australia

2 Microbiology and Immunology Department, University of Melbourne, Royal Parade, Parkville, Victoria 3052, Australia
Proliferative enteropathy (PE) is a complex of diseases of commercial importance to the pig industry. The obligate intracellular bacterium Lawsonia intracellularis is consistently associated with PE and pure cultures of this bacterium have been used to reproduce PE in pigs. In this study $L$. intracellularis bacteria were purified directly from PE-affected tissue. DNA extracted from purified bacteria was used to construct a partial genomic library which was screened using sera from $L$. intracellularis-immunized rabbits. Two seroreactive recombinant clones were identified, one of which expressed proteins of 10 and $60 \mathrm{kDa}$. The sequence of the insert from this clone, pISI-2, revealed ORFs with sequence similarity to the groESIEL operon of Escherichia coli, the 505 ribosomal proteins L21 and L27 of E. coli, a GTPbinding protein of Bacillus subtilis and a possible protoporphyrinogen oxidase, HemK, of E. coli. Primers designed from unique sequences from the pISI-2 insert amplified DNA from infected, but not non-infected, porcine ilea; the amplicon sequence obtained from tissue-cultured $L$. intracellularis was identical to the corresponding sequence in pISI-2, confirming the origin of the clone. The sequence of $L$. intracellularis GroEL and other GroEL sequences in the databases were used to construct a partial phylogenetic tree. Analysis of the GroEL sequence relationship suggested that $L$. intracellularis is not significantly related to other organisms whose GroEL sequences are held in the databases and supports previous data from 165 sequence analyses suggesting that $L$. intracellularis is a member of a novel group of enteric pathogens.

Keywords: proliferative enteropathy, Lawsonia intracellularis, groE operon, heat-shock protein

\section{INTRODUCTION}

Proliferative enteropathy (PE) is a commercially important disease in the pig industry, with the potential to affect large numbers of pigs, particularly those reared intensively. The disease is characterized by proliferation of intestinal mucosa enterocytes leading to gross thickening of the ileal wall (Rowland \& Lawson, 1974). This

\footnotetext{
†Present address: Department of Perinatal Medicine, The Royal Women's Hospital, 132 Grattan Street, Carlton, Victoria 3053, Australia.

Abbreviation: PE, proliferative enteropathy.

The GenBank accession number for the sequence reported in this paper is U45241.
}

pathology is accompanied by a marked reduction in weight gain by affected pigs. Severely affected pigs scour and sudden death is not uncommon.

A consistent feature of $\mathrm{PE}$ is the presence of curved Gram-negative bacilli within the cytoplasm of immature crypt epithelial cells of the ileum (Rowland \& Lawson, 1974). These intracellular bacteria have not yet been cultured in cell-free media but can be maintained in a rat enterocyte cell line (McOrist et al., 1990; Lawson et al., 1993). Bacterial isolates grown in vitro have been used to reproduce PE in pigs (McOrist et al., 1993) and hamsters (Jasni et al., 1994). Other bacteria may have a role in the establishment of PE, as attempts at reproducing the disease in gnotobiotic pigs using a pure bacterial inoculum have failed (McOrist et al., 1993, 1994). 
However, the oxygen tension and crypt architecture in the intestines of gnotobiotic pigs may be responsible for this effect (McOrist et al., 1993, 1994).

The taxonomy of the bacterium and the relationship between the organism and the pathology of PE have not been fully resolved. Previous studies of this intracellular bacterium isolated from lesions in pigs indicate that it belongs to a taxonomic group distinct from all known bacteria (McOrist et al., 1990; Gebhart et al., 1993). Based on classification similarities, this organism was formerly known as Campylobacter-like organism, but was given the vernacular name 'Ileal symbiont intracellularis' until further clarification of its taxonomic position (Gebhart et al., 1993). Analysis of the $16 \mathrm{~S}$ rRNA sequence from 'Ileal symbiont intracellularis' has revealed the highest sequence similarity, $91 \%$ (Gebhart et al., 1993; McOrist et al., 1995), to that of Desulfovibrio desulfuricans and greater than $86 \%$ sequence similarity to $16 \mathrm{~S}$ rRNA sequences of all members of the family Desulfovibrionaceae (Gebhart et al., 1993). Similar results have been found by Fox et al. (1994). However, physiological classification characteristics of $D$. desulfuricans indicate that this species is considerably different to 'Ileal symbiont intracellularis' (Gebhart et al., 1993; Fox et al., 1994; McOrist et al., 1995). McOrist et al. (1995) have suggested that 'Ileal symbiont intracellularis' belongs to a new genus and have renamed this bacterium Lawsonia intracellularis. The identification of genes from L. intracellularis may provide a further insight into classification of this bacterium and its relationship with $\mathrm{PE}$.

Although there are reports from research groups successfully co-culturing $L$. intracellularis, in our experience co-culture of this bacterium in rat enterocytes does not produce large numbers and alternative methods are being sought to generate material for taxonomic, diagnostic and pathogenesis studies. The diagnosis of disease caused by newly identified pathogens which are difficult to culture, such as $L$. intracellularis, requires the generation of reagents which may include recombinant proteins for serological investigations and/or unique DNA sequences for use in PCR or DNA probe-based assays. Characterization of the gene products from $L$. intracellularis may also assist studies to identify the mechanisms that influence the progression of infection. In this study, we have constructed a partial library of $L$. intracellularis and have begun analysing $L$. intracellularis gene sequences. We report on several previously unidentified gene sequences from this novel pathogen.

\section{METHODS}

Pig ilea samples. Sections of grossly thickened pig ilea were collected post-mortem and serious generalized lesions associated with PE confirmed by histopathology. The presence of L. intracellularis in the ilea was confirmed using modified acid-fast Ziehl-Neelsen staining and immunofluorescence staining using specific mAbs from Dr Steve McOrist (University of Edinburgh, UK) as described by McOrist et al.
(1987). Ilea from five pigs not infected with the disease were obtained from a quarantined piggery which has had only isolated cases of PE (Victorian Institute of Animal Science, Werribee, Australia).

Isolation of $L$. intracellularis from infected porcine ilea. Infected ilea were collected from pigs and stored at $-80^{\circ} \mathrm{C}$. Ileal samples were thawed and $L$. intracellularis bacteria were isolated from mucosal scrapings taken from the infected intestinal wall. Infected mucosa were homogenized repeatedly with PBS in an omnimixer (Sorvall) to release the intracellular bacteria and contaminating cellular debris was removed by low-speed centrifugation steps as described by Holyoake $e t$ al. (1994). The supernatant obtained was filtered through $3,1 \cdot 2$ and $0.8 \mu \mathrm{m}$ filters (Millipore) and the filtrate centrifuged at $8000 \mathrm{~g}$ for $30 \mathrm{~min}$, resulting in a small pellet of L. intracellularis bacteria. The bacteria were further purified using a Percoll (Pharmacia) gradient as described by Holyoake et al. (1994). The purity of the isolated bacteria $(>95 \%$ ) was assessed by reacting a portion with $\mathrm{mAbs}$ to L. intracellularis (McOrist $e$ t al., 1987) and by phase-contrast microscopy to reveal any contaminating bacteria or gut debris present.

Cell line. L. intracellularis bacteria purified from the ilea of infected pigs were co-cultured with the rat ileum enterocyte cell line IEC 18 and kindly supplied by Alison Collins (Department of Agriculture, Bendigo, Australia). The isolates used and the conditions for growth and maintenance of this co-culture are described by Collins et al. (1996).

Isolation of genomic DNA. L. intracellularis genomic DNA was isolated from Percoll-gradient-purified bacteria using the method described by Anderson et al. (1984). This DNA preparation was used to construct a genomic library (as described below). For use in PCR, DNA was isolated from PBS-washed mucosa taken from normal and proliferated pig ilea. Co-cultured L. intracellularis within the IEC rat enterocyte cell line was boiled for $10 \mathrm{~min}$ with $0.3 \%$ SDS followed by phenol/chloroform extraction and ethanol precipitation of DNA before use in PCR.

Antisera. Antisera to L. intracellularis were raised in rabbits and pigs. Rabbits were injected intramuscularly with a preparation of Percoll-gradient-purified L. intracellularis bacteria mixed at a ratio of $1: 1$ with a double-emulsion made by processing with oil adjuvant (Freund's incomplete adjuvant) and then with an equal volume of Tween 80 enhancer. Two $3 \mathrm{ml}$ injections, containing approximately $9 \mathrm{mg}$ protein, were given 4 weeks apart. Blood samples were collected from the ear vein prior to immunization and 2 weeks following the second injection. A 6-week-old pig was hyperimmunized by intramuscular injection of Percoll-gradient-purified $L$. intracellularis bacteria prepared with Freund's incomplete adjuvant. Three injections of the prepared antigen were administered 4 weeks apart and blood was collected from the anterior vena cava 2 weeks following the final injection.

Library construction and immunological screening. L. intracellularis DNA was digested with EcoRI (Promega) and then ligated to EcoRI-digested and calf intestinal phosphatase (Promega)-treated $\lambda$ ZAP II (Stratagene), and packaged using Gigapack packaging extracts (Stratagene) according to the manufacturer's recommendations. Phage-infected $E$. coli XL1 Blue (Stratagene) was grown overnight on Luria-Bertani (LB) agar at a density of 2000 plaque-forming units (p.f.u.) per $150 \mathrm{~mm}$ plate and phage were transferred to nitrocellulose filters (Hybond C; Amersham). Transferred phage were denatured and prepared for immunohybridization as described by Moses et al. (1989). Filters were screened using the 
rabbit antiserum (1:100 dilution in $1 \%$ gelatin/PBS). Horse radish peroxidase (HRP)-conjugated goat anti-rabbit immunoglobulin (Silenus; 1:3000 dilution in 1\% gelatin/PBS) was used to detect seroreactive plaques followed by colour development in a solution of $0.05 \%$ 4-chloro-1-naphthol (Sigma) $/ 0 \cdot 015 \% \mathrm{H}_{2} \mathrm{O}_{2}$ in a $5: 1$ solution of Tris-bufferedsaline/methanol. Positive plaques identified in a primary screen were picked, replated at a lower density and rescreened until individual positive plaques were identified. Phagemid clones were excised according to the manufacturer's protocols (Stratagene).

SDSPAGE. E. coli transformed with pBluescript $\mathrm{SK}(-)$ (Stratagene) and clones pISI-1 and pISI-2 were grown to stationary phase in $10 \mathrm{ml} \mathrm{LB} /$ ampicillin broth. The cell pellets from $0.2 \mathrm{ml}$ aliquots of culture were resuspended in $50 \mu \mathrm{l}$ sample buffer $(62.5 \mathrm{mM} \mathrm{HCl}, 2 \%$ SDS, $10 \%$ glycerol, $5 \% 2-$ mercaptoethanol, $0.002 \%$ bromophenol blue, $\mathrm{pH} \mathrm{6.8)}$ and heated to $95^{\circ} \mathrm{C}$ for $5 \mathrm{~min}$ before separating solubilized proteins electrophoretically on a $12 \%$ SDS-PAGE vertical slab gel (Laemmli, 1970). Proteins were visualized by staining with Coomassie blue R250.

Western immunoblotting. Proteins were electrophoretically transferred to Immobilon-P PVDF membrane (Millipore) in a buffer containing CAPS ( $\mathrm{pH} 11$ ) and $10 \%$ methanol as described by Towbin et al. (1979). The membranes were blocked with $10 \%$ skim milk powder in PBS containing $0.05 \%$ Tween-20 (PBST) and then incubated in either rabbit or pig antisera for $1 \mathrm{~h}$ followed by washing twice in $0.1 \%$ skim milk powder/PBST. Rabbit antisera were used at a dilution of $1: 2000$ in $1 \%$ skim milk powder, PBST. Diluted pig sera $(1: 1000)$ were pre-absorbed with an $E$. coli $(\mathrm{DH} 5 \alpha)$ lysate for $1 \mathrm{~h}$ at room temperature prior to adding to the membranes at a final dilution of $1: 10000$. HRP-conjugated goat anti-rabbit immunoglobulins (Silenus), diluted 1:3000, were used to detect rabbit antibodies. Similarly, HRP-conjugated swine immunoglobulins (DAKO) were applied at a dilution of $1: 1000$ to detect porcine antibodies. Seroreactive products were detected by Enhanced Chemiluminescence (ECL; Amersham) according to the manufacturer's protocols.

Exonuclease deletions. The plasmid clones pISI-2 and pISI-42, containing identical $5 \mathrm{~kb}$ inserts in opposite orientations, were subjected to deletion analysis using the Erase-a-Base Kit and the protocol supplied (Promega). The unique KpnI and SalI sites in the polylinker of pBluescript were used to provide the overhangs required for exonuclease III digestion. After treatment with these enzymes the linearized DNA was digested with exonuclease at $37^{\circ} \mathrm{C}$ and stopped at intervals of $45 \mathrm{~s}$, religated and transformed into E. coli $\mathrm{DH} 5 \alpha$.

Plasmid DNA isolation and analysis. Plasmid DNA was purified from $5 \mathrm{ml} \mathrm{E}$. coli DH $5 \alpha$ cultures by the modified alkaline lysis, PEG precipitation protocol supplied with the PRISM Ready Reaction DyeDeoxy Terminator Cycle Sequencing Kit (Applied Biosystems). Restriction endonucleases, other enzymes and reaction buffers were from Promega. Methods used for DNA treatments with restriction endonucleases or modification enzymes were from Sambrook et al. (1989).

DNA sequencing. Plasmid DNA was isolated and sequenced using the PRISM Ready Reaction DyeDeoxy Terminator Cycle Sequencing Kit (Applied Biosystems) according to the manufacturer's protocol. Clones were sequenced using the M13 universal sequencing primer (Pharmacia). Sequence analysis was performed using the Australian National Genomic Information Service (ANGIS) and DNA and protein database searches were performed using the BLAST (Altschul $e t$ al., 1990) network services. GCG programs (Wisconsin Package Version 8) were used to produce contiguous sequence and CLUSTAL w (Thompson et al., 1994) was used to align the cloned sequences with similar bacterial sequences currently available in the databases.

PCR. Primers designed to amplify a 720 bp fragment of pISI-2, including sequence of a putative $50 \mathrm{~S}$ ribosomal protein L21-L27 gene cluster, were ISI50S2F $\left(5^{\prime}\right.$ GAAGAAGTCATTACACTCC) and ISI50S2R (5' CATTCTAAAGATAAAGTTCC. Cycling was performed using the GeneAmp PCR System 9600 (Perkin Elmer) with the following conditions: $95^{\circ} \mathrm{C}$ for $10 \mathrm{~s}, 80^{\circ} \mathrm{C}$ for $2 \mathrm{~min}$, followed by 35 cycles of $95^{\circ} \mathrm{C}$ for $15 \mathrm{~s}, 50^{\circ} \mathrm{C}$ for $15 \mathrm{~s}$ and $72^{\circ} \mathrm{C}$ for $30 \mathrm{~s}$. Each $50 \mu \mathrm{l}$ reaction contained $200 \mu \mathrm{M}$ dNTPs, $1 \times T$ th reaction buffer, $1 \mu \mathrm{M}$ each primer and DNA. Two units of $T t h$ thermostable polymerase (Toyobo) was added to each of the reaction mixtures held at $80^{\circ} \mathrm{C}$ prior to cycling. The PCR product obtained from cocultured $L$. intracellularis was sequenced directly to confirm the origin of the library clone (pISI-2). Following amplification, salts and nucleotides were removed from the PCR reaction using Wizard DNA clean-up resin (Promega) and the $720 \mathrm{bp}$ amplicon was sequenced using the same primers.

Phylogenetic tree analysis. GroEL protein alignments and evolutionary distances were kindly provided by Dr Alejandro Viale (Universidad Nacional de Rosario, Argentina; Ferreyra et al., 1993; Viale et al., 1994). The Alignment Editor 2 (AE2) program was used to insert the GroEL sequence from $L$. intracellularis and other GroEL sequences submitted recently to GenBank. Following visual inspection, gaps were inserted into sequences to improve the alignment. An aligned column of amino acid residues which included a gap in any one sequence was excluded from the alignment prior to phylogenetic tree construction. This included the last 21 amino acid residues of each sequence in the alignment (numbering according to the E. coli GroEL sequence). Comparisons were made from an alignment of 506 predicted amino acids for each entry. The GenBank database accession numbers and sources of GroEL sequences used for this phylogenetic study are given in Table 1.

Phylogenetic trees based on GroEL amino acid sequences were constructed using the PHYLIP programs (J. Felsenstein, University of Washington, USA). The GroEL alignment was bootstrapped 100 times using SEQBOOT. The 100 data sets generated were put into the distance matrix program PROTDIST. Distance matrix data were arranged into a tree file using the neighbour-joining method (NEIGHBOR). A consensus tree of the data set was produced by the program CONSENSE. The phylogenetic tree was finally arranged and edited using TreeTool 2.0 (Mike Maciukenas, University of Illinois, USA). The partial prokaryotic $16 \mathrm{~S}$ rRNA tree was extracted from the Ribosomal Database Project (RDP, University of Illinois, USA).

\section{RESULTS}

\section{Library screening}

DNA isolated from Percoll-gradient-purified L. intracellularis bacteria was fully digested with EcoRI and ligated to EcoRI-digested $\lambda$ ZAP II to produce a partial genomic library. Approximately 2000 plaques were transferred to nitrocellulose and reacted with rabbit antiserum specific for L. intracellularis. Plasmids were excised from 18 plaques which were positive in this 
Table 1. Sources of GroEL sequences used for sequence alignments and phylogenetic tree

\begin{tabular}{|c|c|c|}
\hline Organism & $\begin{array}{c}\text { GenBank } \\
\text { accession no. }\end{array}$ & Reference \\
\hline Lawsonia intracellularis & U45241 & This publication \\
\hline \multicolumn{3}{|l|}{$\alpha$-Proteobacteria } \\
\hline Sinorbizobium meliloti & M94192 & Rasunganwa \& Gupta (1993) \\
\hline Agrobacterium tumefaciens & X68263 & Segal \& Ron (1993) \\
\hline Rhizobium leguminosarum & L20775 & Wallington \& Lund (1994) \\
\hline Brucella abortus & L09273 & Gor \& Mayfield (1992) \\
\hline Bartonella bacilliformis & M98257 & Unpublished data \\
\hline Bradyrbizobium japonicum & Z22604 & See Viale et al. (1994) \\
\hline Zymomonas mobilis & L11654 & Barbosa et al. (1994) \\
\hline Ehrlichia chaffeensis & L10917 & See Viale et al. (1994) \\
\hline Cowdria ruminantium & U13638 & Lally et al. (1995) \\
\hline \multicolumn{3}{|l|}{$\beta$-Proteobacteria } \\
\hline Neisseria flavescens & Z22955 & Pannekoek et al. (1995) \\
\hline Neisseria meningitidis & $\mathrm{Z} 22956$ & Pannekoek et al. (1995) \\
\hline Neisseria gonorrboeae & Z23008 & Pannekoek et al. (1995) \\
\hline \multicolumn{3}{|l|}{$\gamma$-Proteobacteria } \\
\hline Chromatium vinosum & M99443 & Ferreyra et al. (1993) \\
\hline Legionella micdadei & $\mathrm{X} 57520$ & See Ferreyra et al. (1993) \\
\hline Legionella pneumophila & M31918 & See Viale et al. (1994) \\
\hline Coxiella burnetii & M20482 & See Ferreyra et al. (1993) \\
\hline Salmonella typhi & U01039 & Lindler \& Hayes $(1994\rangle$ \\
\hline Escherichia coli & $\mathrm{X} 07850$ & See Viale et al. (1994) \\
\hline Yersinia enterocolitica & $\mathrm{X} 68526$ & Unpublished data \\
\hline Symbiont of Acyrthosiphon pisum & $\mathrm{X} 61150$ & See Viale et al. (1994) \\
\hline Haemophilus ducreyi & M91030 & See Viale et al. (1994) \\
\hline Pseudomonas aeruginosa & M63957 & See Viale et al. (1994) \\
\hline \multicolumn{3}{|l|}{$\delta / \varepsilon$-Proteobacteria } \\
\hline Helicobacter pylori & $X 73840$ & See Viale et al. (1994) \\
\hline \multicolumn{3}{|l|}{ Bacteroides } \\
\hline Porphyromonas gingivalis & D17398 & Maeda et al. (1994) \\
\hline \multicolumn{3}{|l|}{ Chlamydiae } \\
\hline Chlamydia trachomatis & M31739 & See Ferreyra et al. (1993) \\
\hline Chlamydia psittaci & X51404 & See Ferreyra et al. (1993) \\
\hline Chlamydia pneumoniae & M69217 & See Viale et al. (1994) \\
\hline \multirow{2}{*}{\multicolumn{3}{|c|}{$\begin{array}{l}\text { Firmicutes (Gram-positive bacteria) } \\
\text { (Low G }+\mathrm{C} \text { content) }\end{array}$}} \\
\hline & & \\
\hline Clostridium perfringens & X62914 & See Ferreyra et al. (1993) \\
\hline Clostridium acetobutylicum & M74572 & See Ferreyra et al. (1993) \\
\hline Bacillus stearothermophilus & L10132 & See Viale et al. (1994) \\
\hline Bacillus subtilis & M81132 & See Ferreyra et al. (1993) \\
\hline Staphylococcus aureus & D14711 & Ohta et al. (1993) \\
\hline Lactococcus lactis & X71132 & Kim \& Batt (1993) \\
\hline \multicolumn{3}{|l|}{ (High $\mathrm{G}+\mathrm{C}$ content) } \\
\hline Streptomyces coelicolor & X75206 & Duchene et al. (1994) \\
\hline Streptomyces albus & M76658 & See Viale et al. (1994) \\
\hline Mycobacterium tuberculosis & M17705 & Thole et al. (1987) \\
\hline Mycobacterium leprae & M14341 & See Viale et al. (1994) \\
\hline Mycobacterium paratuberculosis & $\mathrm{X} 74518$ & Colston et al. (1994) \\
\hline \multicolumn{3}{|l|}{ Cyanobacteria } \\
\hline Cyanidium caldarium & $\mathrm{X} 62578$ & See Viale et al. (1994) \\
\hline Synechococcus sp. & M58751 & See Ferreyra et al. (1993) \\
\hline Synechocystis sp. & M57517 & See Ferreyra et al. (1993) \\
\hline \multicolumn{3}{|l|}{ Spirochaetes } \\
\hline Treponema pallidum & X54111 & See Viale et al. (1994) \\
\hline Borrelia burgdorferi & $\times 54059$ & See Viale et al. (1994) \\
\hline Leptospira interrogans & L14682 & See Viale et al. (1994) \\
\hline
\end{tabular}


(a)

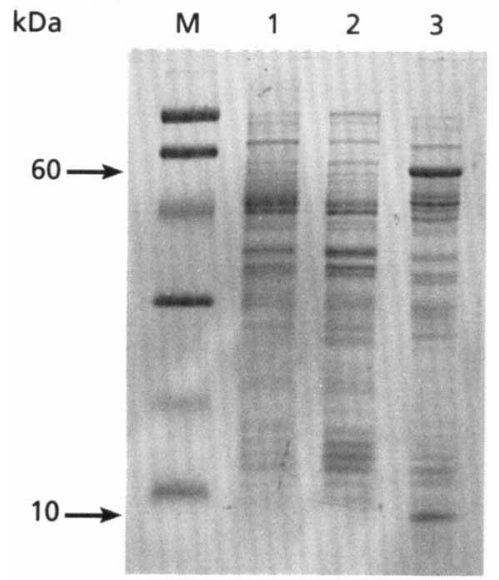

(b)

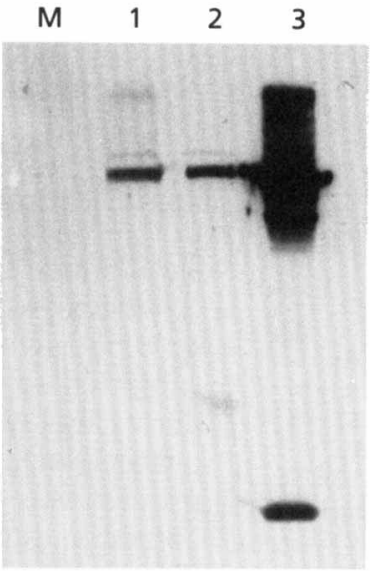

Fig. 1. SDS-PAGE analysis of pISI-1 and pISI2. (a) Coomassie blue R250-stained gel showing the profile of proteins expressed by $\mathrm{DH} 5 \alpha$ transformed with the vector pBluescript (lane 1), pISI-1 (2) and pISI-2 (3). (b) Western immunoblot screened by antisera raised in rabbits. The antigens of approximately 10 and $60 \mathrm{kDa}$ expressed by pISI-2 in DH5 $\alpha$ are indicated. Low molecular mass standards (lanes $M$ ) are rabbit muscle phosphorylase b (94000 Da), bovine serum albumin $(67000 \mathrm{Da})$, ovalbumin $(43000 \mathrm{Da})$, bovine erythrocyte carbonic anhydrase $(30000 \mathrm{Da})$ and bovine $\alpha$-lactalbumin (14000 Da). (a)

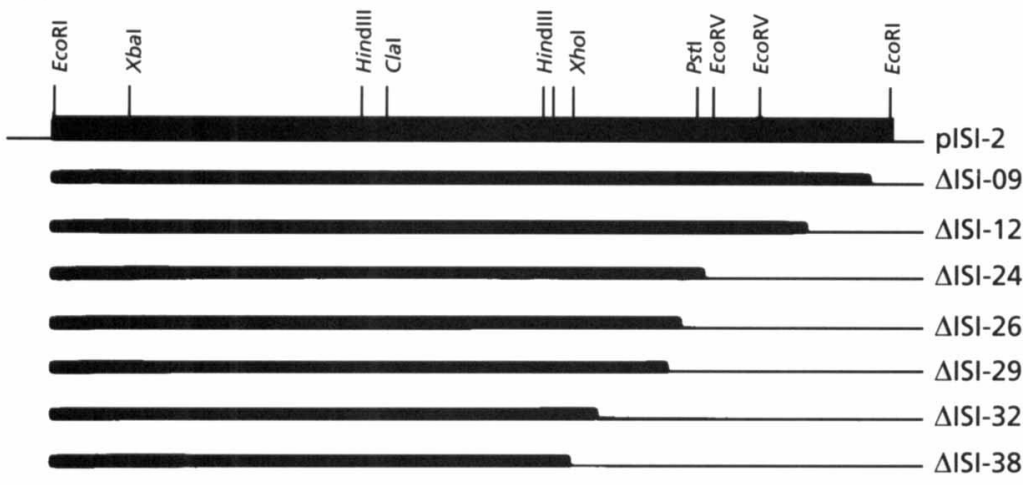

(b)

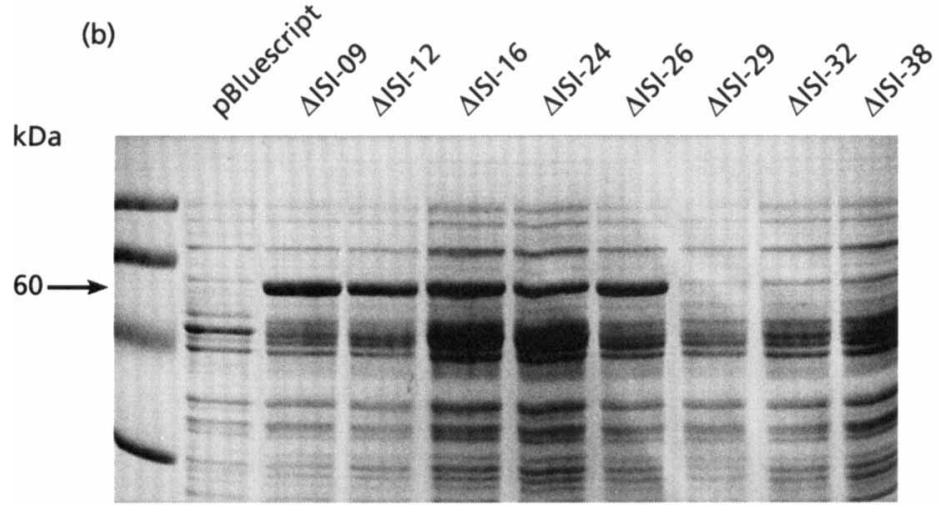

Fig. 2. Restriction map of pISI-2. (a) Exonuclease deletions derived from pISI-2 are indicated as bold lines below the restriction map. (b) SDS-PAGE profile of the nested deletions stained with Coomassie blue R250. Expression of the $60 \mathrm{kDa}$ protein from $L$. intracellularis in $\mathrm{DH} 5 \alpha$ is not evident when $1.4 \mathrm{~kb}$ was deleted, corresponding to deletion derivative $\Delta|S|-29$. Proteins expressed by $\mathrm{DH} 5 \alpha$ transformed with pBluescript are shown. assay and produced one of two distinct EcoRI restriction patterns. These E. coli XL-1 Blue plasmids contained inserts of either 9 or $5 \mathrm{~kb}$. An $E$. coli clone from each class was chosen for further analysis and named pISI-1 ( $9 \mathrm{~kb}$ insert) and pISI-2 ( $5 \mathrm{~kb}$ insert $)$. Based on restriction enzyme digests, a third clone pISI-42, which contained an identical insert to pISI-2 in the opposite orientation, was also chosen for further analysis.
The E. coli clones were analysed by SDS-PAGE and Western immunoblotting. Repeated analysis of $E$. coli(pISI-1) did not reveal any novel antigens in the profile produced by either SDS-PAGE or Western immunoblotting (Fig. 1). E. coli(pISI-2) expressed antigens of approximately 10 and $60 \mathrm{kDa}$. These were detected by staining with Coomassie blue R250 (Fig. 1a) and with either the rabbit antisera (Fig. 1b) or sera raised 


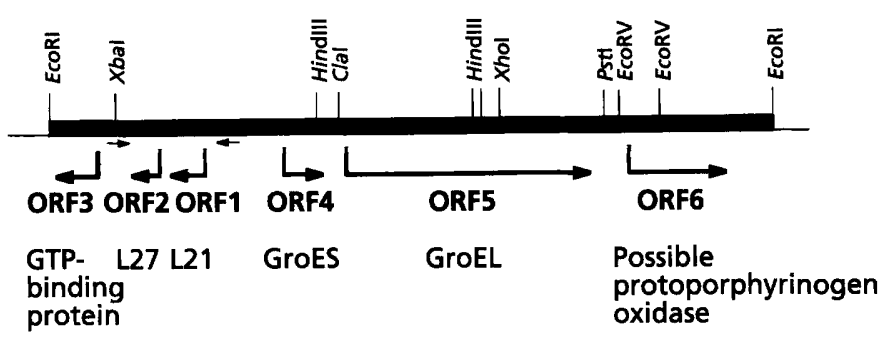

Fig. 3. Gene arrangement of the $5 \mathrm{~kb}$ clone from $L$. intracellularis. The position and relative size of the ORFs are given by the large arrows under the restriction map. The names given to each ORF have been derived from homology searches with sequences submitted to GenBank. ORF1, ORF2 and ORF3 are contiguous as are ORF4, ORF5 and ORF6. Small facing arrows indicate the positions of the primers used to amplify a PCR product which includes the gene cluster with sequence similarity to the $50 S$ ribosomal proteins L21 and L27.

in the hyperimmunized pig (data not shown). The $10 \mathrm{kDa}$ protein was not detected in an E. coli control containing pBluescript without an insert. However, there was some cross-reactivity of the antisera with an $E$. coli protein of approximately $60 \mathrm{kDa}$ (Fig. 1b). E. coli(pISI-42), in which the insert orientation was inverted relative to the $l a c Z$ promoter of pBluescript, also expressed the $60 \mathrm{kDa}$ protein (data not shown).

\section{Identification of the $60 \mathrm{kDa}$ protein encoded by pISI-2}

To identify the gene encoding the $60 \mathrm{kDa}$ protein and other gene sequences, a restriction map of the $5 \mathrm{~kb}$ insert of pISI-2 was generated (Fig. 2) and the clone was subjected to deletion analysis (Fig. 2a). The deletion derivatives were analysed by SDS-PAGE for expression of the $60 \mathrm{kDa}$ protein (Fig. 2b). Expression of the $60 \mathrm{kDa}$ protein was not detected when $1.4 \mathrm{~kb}$ were deleted, corresponding to deletion derivative $\Delta I S I-29$ (Fig. 2). The nucleotide sequences of deletion derivatives $\Delta I$ SI26, $\Delta$ ISI-29 and $\Delta$ ISI-32 were compared with sequences held by the NCBI database using the BLAST network service (Altschul et al., 1990) and revealed sequence similarity to a gene encoding the molecular chaperonin GroEL of E. coli and of many other species. Further sequencing revealed that a homologue of the groES/EL operon of $E$. coli was present within the $5 \mathrm{~kb}$ insert of pISI-2 (Fig. 3).

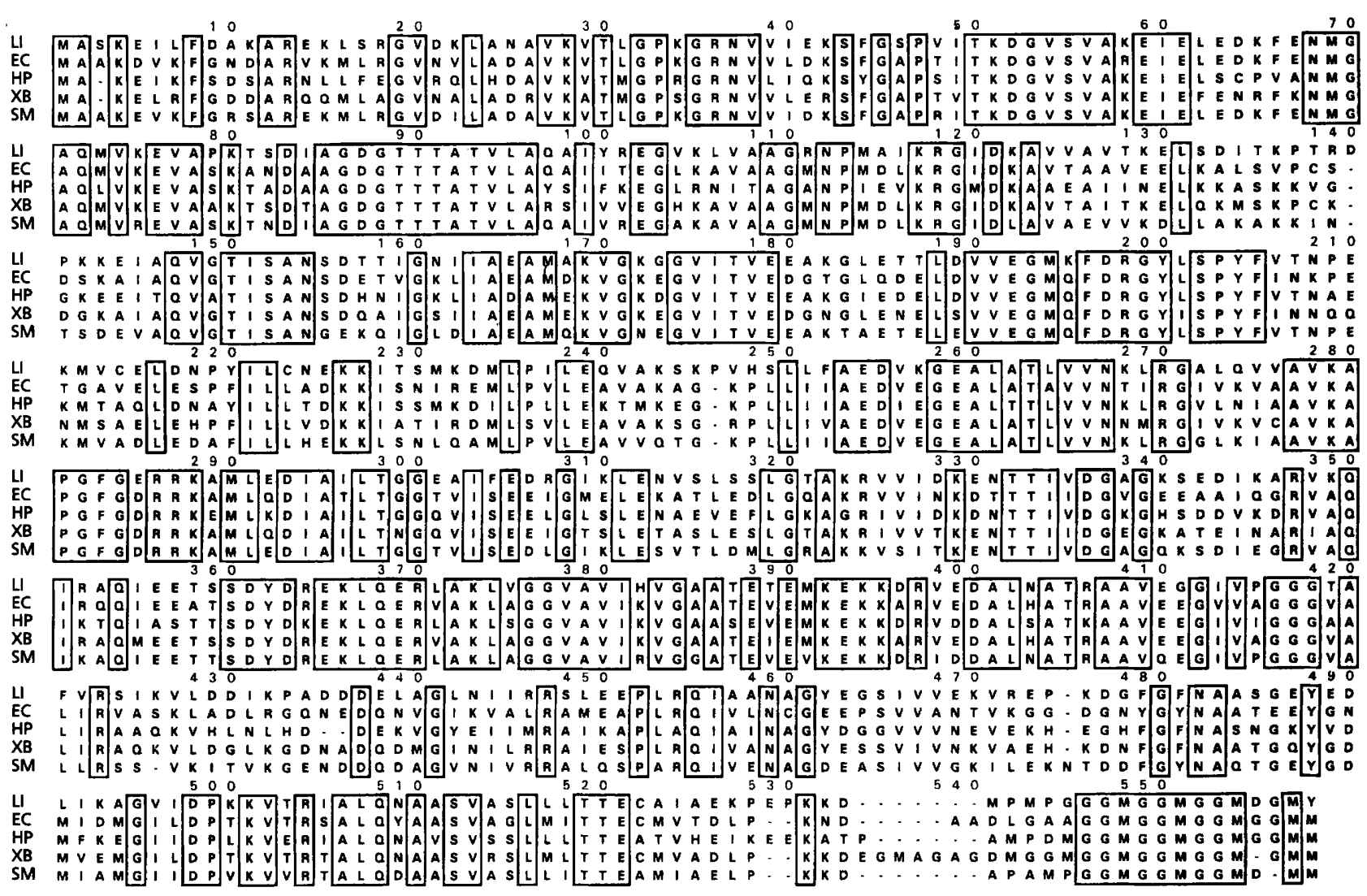

Fig. 4. Alignment of the predicted amino acid sequences of the GroEL-like protein from L. intracellularis (LI) and $E$. coli (EC), H. pylori (HP), the endosymbiont of $A$. proteus known as X-bacteria (XB) and S. meliloti (SM). Sequences were extracted from the GenBank database using the appropriate accession numbers listed in Table 1 and were aligned using CLUSTAL W (Thompson et al., 1994). Boxes indicate identical amino acids in all sequences. 
(a) GroEs

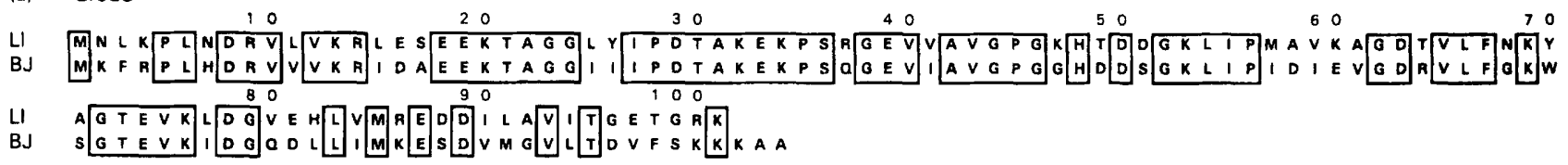

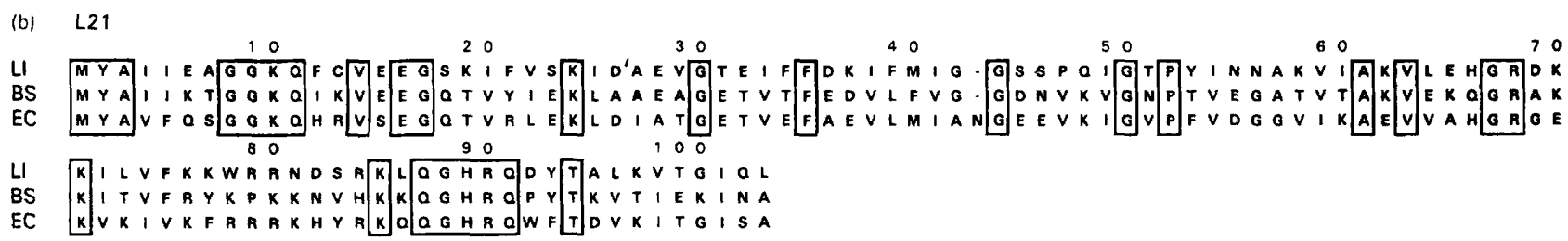

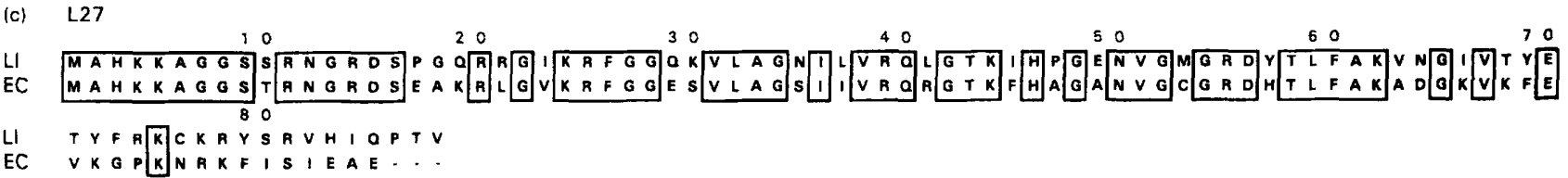

(d) Putative GTP-binding protein

LI

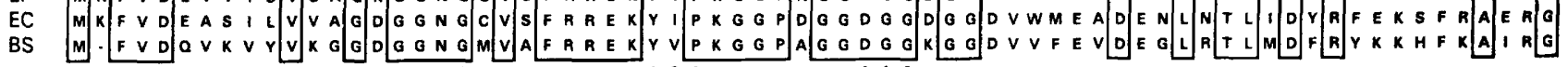

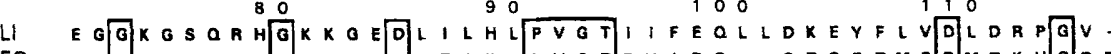

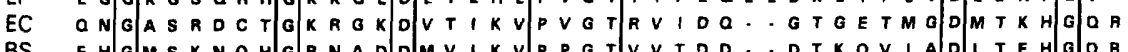

BS EHGJSKNOHGRNADDMVIKVPPGTVVTDD.. DTKOVIADLTEHGOA

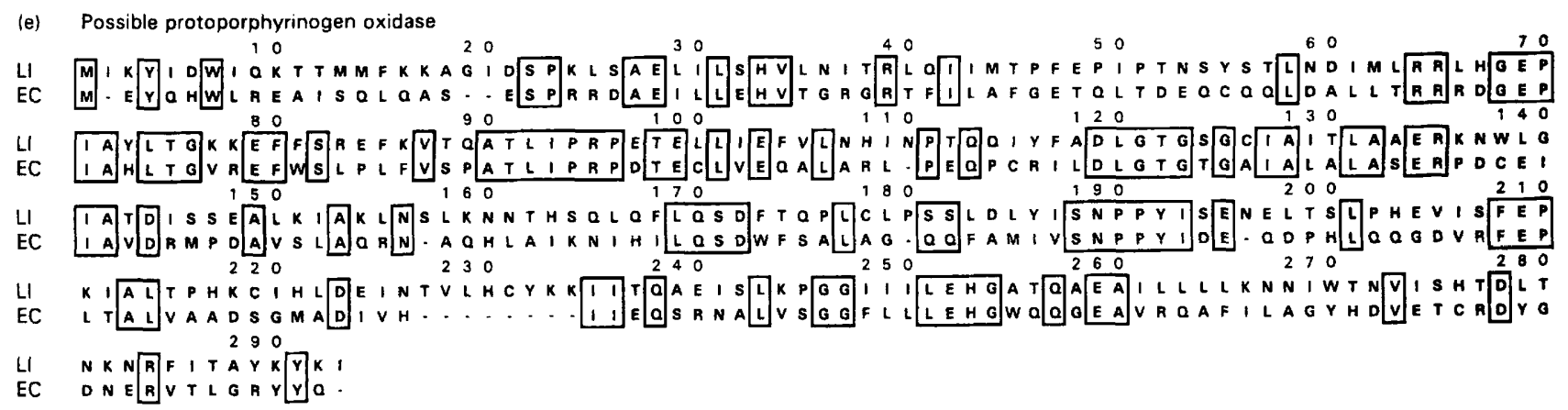

Fig. 5. Alignments of predicted amino acid sequences. (a) GroES from L. intracellularis (LI) and B. japonicum (BJ). (b, c) $50 S$ rRNA proteins L21 (b) and L27 (c) from $L$. intracellularis (LI), E. coli (EC) and B. subtilis (BS). (d) Partial sequence from the putative GTP-binding protein of $L$. intracellularis (LI) and sequence from the GTP-binding protein of $B$. subtilis (BS) and the ORF of $E$. coli (EC). (e) Possible protoporphyrinogen oxidase from $L$. intracellularis (LI) and $E$. coli (EC). Boxes indicate identical amino acids in all sequences.

The molecular chaperonins GroES and GroEL of E. coli have molecular masses of 10.4 and $57 \cdot 3 \mathrm{kDa}$, respectively (Hemmingsen et al., 1988). The $60 \mathrm{kDa}$ protein of $L$. intracellularis expressed by the E. coli(pISI-2) clone (Fig. 1) is consistent with the predicted size of GroEL. Sequence analysis revealed that the deletion derivative $\Delta \mathrm{ISI}-29$, which does not express the $60 \mathrm{kDa}$ protein (Fig. 2 ), has the predicted termination codon removed from the groEL-like sequence. The high level of expression of the $60 \mathrm{kDa}$ protein is halted, presumably due to the continuation of transcription through to some point within pBluescript whereby the accumulation of the $60 \mathrm{kDa}$ protein is not seen on the SDS-PAGE profile. Hence, it is likely that the $60 \mathrm{kDa}$ polypeptide expressed by $E$. coli(pISI-2) (Fig. 1 ) is an $L$. intracellularis homologue of E. coli GroEL.

\section{Sequence analysis of the $5 \mathbf{~ k b}$ clone}

The exonuclease derivatives of pISI-2 and pISI-42 were sequenced. Six ORFs (Fig. 3) were identified on pISI-2 and compared with sequences held by the NCBI database as described above.

ORF1 (Fig. 3) is $309 \mathrm{nt}$ long with a deduced amino acid sequence homologous to a $50 \mathrm{~S}$ ribosomal protein, L21, of $E$. coli. It is predicted to encode a peptide of 102 aa with a molecular mass of $11516 \mathrm{Da}$. ORF2 has an ATG start codon $9 \mathrm{bp}$ downstream from the putative TAA 


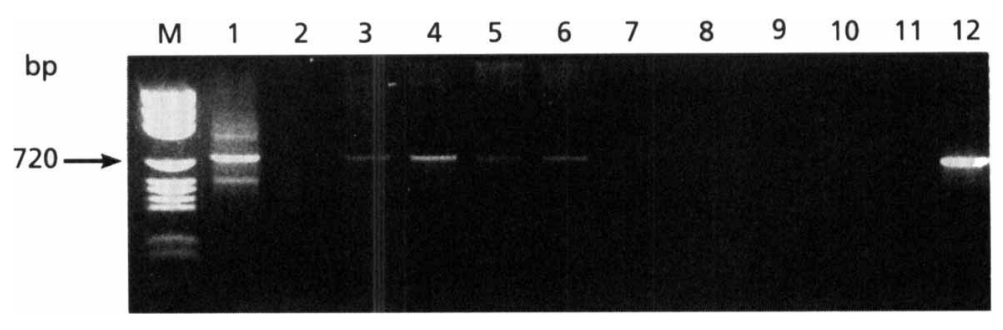

Fig. 6. PCR amplicons generated using primers ISI5OS2F and ISI5OS2R. The amplicons in lane 1 are from tissue-cultured $L$. intracellularis in the IEC rat enterocyte cell line. PCR products were not amplified from the IEC cell line cultured without $L$. intracellularis bacteria (lane 2). Lanes 3-6 show amplicons from DNA extracted from the ilea of four pigs with characteristic lesions of PE. Lanes 7-11 show that a product was not amplified from DNA extracted from the ilea of five pigs which had no symptoms of an infection of $L$. intracellularis. The PCR product shown in lane 12 was amplified from pISI-2 as a positive control.

stop codon of ORF1. ORF2 is $267 \mathrm{nt}$ long and is predicted to encode a peptide of 88 aa with a molecular mass of $9816 \mathrm{Da}$. The predicted amino acid sequence shares sequence similarity to $\mathrm{L} 27$, another $50 \mathrm{~S}$ ribosomal protein of $E$. coli. The sequences of the ribosomal proteins L21 (GenBank accession no. P02422) and L27 (P02427) of E. coli encode polypeptides of 11.6 and $9 \mathrm{kDa}$, respectively. According to sequence comparisons obtained through the BLAST network server, the highest sequence similarity was found between the Bacillus subtilis L21 homologue (X59528) and ORF1, with 57 and $43 \%$ conservation of the nucleotide and predicted amino acid sequences, respectively. Sequence similarity was highest between E. coli L27 and ORF2 with $63 \%$ matching nucleotides and $58 \%$ conservation of the predicted amino acid sequence.

Contiguous with ORF1 and ORF2, ORF3 is a partial sequence of $345 \mathrm{bp}$ with an ATG start codon $162 \mathrm{bp}$ downstream from a TAA putative stop codon of ORF2. The deduced amino acid sequence of ORF3, which appears to be incomplete, extending beyond the EcoRI cloning site, shares sequence similarity to the $5^{\prime}$ region of the gene encoding an essential GTP-binding protein, Obg, of B. subtilis (Trach \& Hoch, 1989; Welsh et al., 1994), and to an ORF of E. coli (U18997) with matches of 45 and $50 \%$, respectively. The incomplete ORF encodes 115 residues which share sequence similarity with the 428-aa Obg protein of $B$. subtilis which has a calculated molecular mass of $47688 \mathrm{Da}$.

ORF4, ORF5 and ORF6 are contiguous and in the opposite orientation to ORF1, ORF2 and ORF3 (Fig. 3). ORF4 (306 nt) is predicted to encode a peptide of $101 \mathrm{aa}$ with a molecular mass of $10942 \mathrm{Da}$. ORF4 is homologous to E. coli GroES and to other GroES sequences held in the database. The nucleotide sequence sharing the highest level of similarity to ORF4 $(66 \%)$ is the GroES homologue of the facultative intracellular bacterium Francisella tularensis (X98853). The predicted amino acid sequence of ORF4 shares the highest level of sequence similarity $(60 \%)$ with Bradyrhizobium japonicum (P35864) (see Fig. 5).

ORF5 is $1647 \mathrm{nt}$ long, starting with an ATG start codon $147 \mathrm{bp}$ downstream from the TGA stop codon of ORF4. ORF5 is predicted to encode a polypeptide of 548 aa with a molecular mass of $58602 \mathrm{Da}$. The predicted amino acid sequence is homologous to that of $E$. coli GroEL. The nucleotide sequence of ORF5 is most similar to that of X-bacteria $(68 \%)$, an endosymbiont of Amoeba proteus (M86549) and the predicted amino acid sequence is most similar (69\%) to that of Sinorbizobium meliloti (M94192).

ORF6 is $882 \mathrm{nt}$ long, starting 126 bp downstream of the TAG stop codon of ORF5. The predicted polypeptide encoded by ORF6 is 293 aa long with a molecular mass of $33166 \mathrm{Da}$. Homology searches with sequences held in GenBank revealed similarity with a possible protoporphyrinogen oxidase, HemK, of E. coli (U18555) and with a number of other bacterial species.

An alignment of predicted amino acid sequences encoded by ORF5 and the GroEL sequence of E. coli and other bacterial sequences sharing highest sequence similarity, X-bacteria, S. meliloti and Helicobacter pylori, is shown in Fig. 4. Alignments of predicted amino acid sequences encoded by ORF1, ORF2, ORF3, ORF4 and ORF6 with sequences held within GenBank sharing the highest similarity to each is given in Fig. 5. The sequence of the insert of pISI- 2 revealed a $\mathrm{G}+\mathrm{C}$ content of $34 \cdot 2 \mathrm{~mol} \%$.

\section{PCR and sequence confirmation of the source of the PISI-2 DNA}

PCR primers were designed to match regions flanking the L21 and L27 gene sequences (small facing arrows, Fig. 3) and used to amplify sequences present in coculture-derived L. intracellularis (Collins et al., 1996) and from $L$. intracellularis present within infected porcine ilea. The expected $720 \mathrm{bp}$ amplicon was obtained from pre-boiled IEC18 rat enterocytes containing L. intracellularis (Fig. 6, lane 1 ) but not from IEC18 cells alone (Fig. 6, lane 2). Ileum samples from nine pigs, four affected by PE and five histologically normal, were also analysed by PCR. Only DNA extracted from the ilea of pigs affected by PE produced the 720 bp amplicon following PCR (Fig. 6, lanes 3-6). An identical sequence obtained from the amplicon produced from the co-cultured L. intracellularis to that 


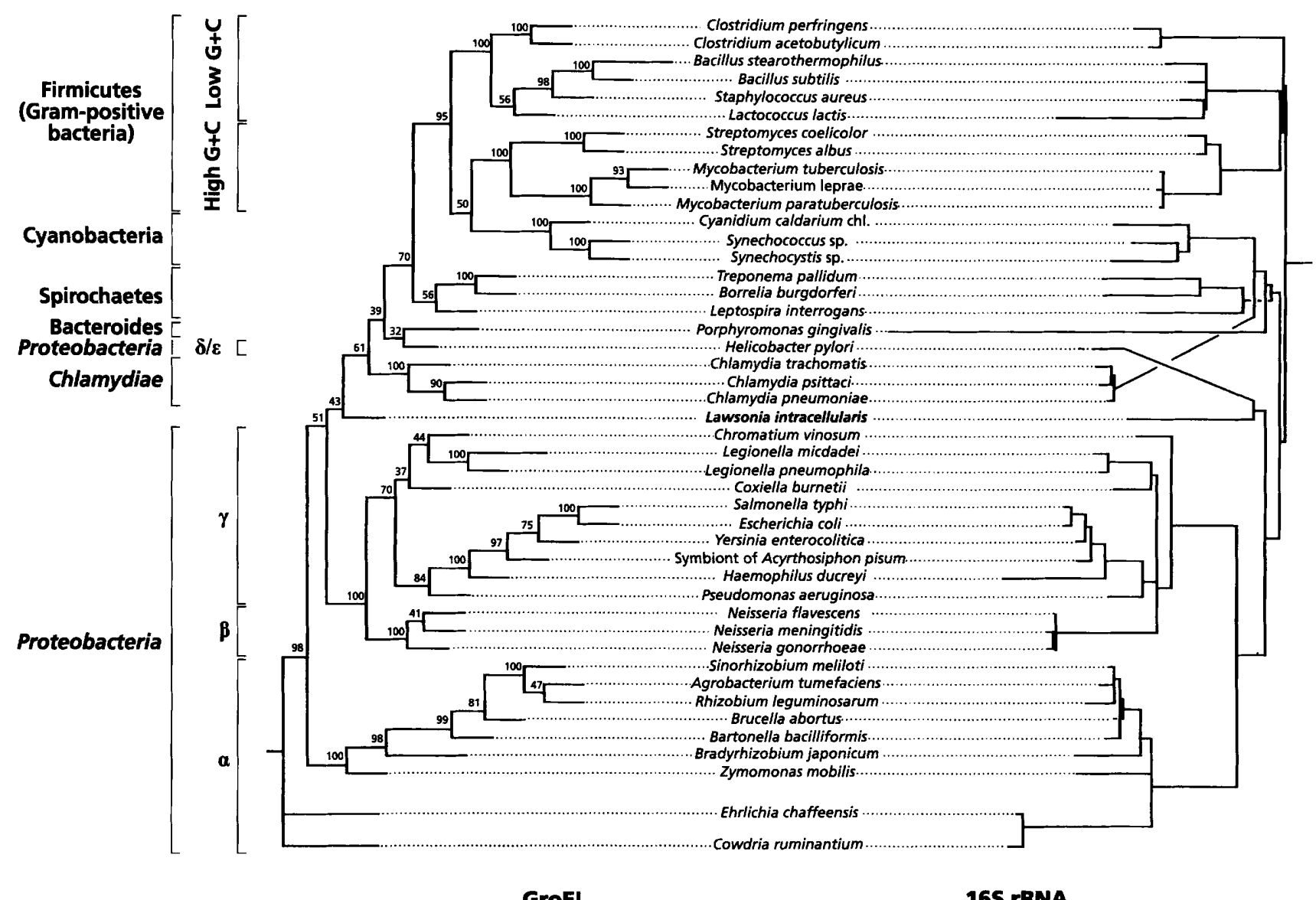

GroEL

$16 S$ rRNA

Fig. 7. Phylogenetic tree based on GroEL relationships. The arrangement is based on the distance matrix method using an alignment of predicted amino acid residues. The numbers given at the ends of branches are obtained by the bootstrap procedure from 100 replicated trees, indicating the number of times the tree branched in this order. The phylogenetic tree based on GroEL relationships is shown here aligned to a partial 16S rRNA tree to demonstrate that the bacteria are similarly assigned in both trees. Some of the branches of the 16S rRNA tree have been crossed, keeping the horizontal distances the same, to fit in with the order given by the phylogenetic tree based on GroEL sequences.

of the corresponding sequence within pISI-2 verified that the $5 \mathrm{~kb}$ clone was isolated from L. intracellularis.

\section{Taxonomic classification of $L$. intracellularis using the predicted amino acid sequence of the GroEL homologue}

The unrooted phylogenetic tree based on predicted GroEL amino acid sequences in Fig. 7 (sources of sequences given in Table 1) was produced using the PHYLIP programs PROTDIST, FITCH and CONSENSE. Similar results were obtained when parsimony analysis was used (data not shown). The phylogenetic tree was compared with a tree produced using 16S rRNA sequences. Both trees show that $L$. intracellularis is taxonomically isolated from other bacteria whose sequences are represented. The nearest neighbour to $L$. intracellularis, according to groEL sequences held in databases, is $\mathrm{H}$. pylori, an intestinal pathogen associated with gastric ulcers. Other close neighbours include the obligate intracellular pathogens of the genus Chlamydia.
CLUSTAL $\mathrm{W}$ analysis of deduced amino acid sequences of GroEL from L. intracellularis and H. pylori (Fig. 4) shows dispersed regions of sequence similarity, including strong sequence conservation at the carboxy terminus of the proteins.

\section{DISCUSSION}

The diagnosis of PE is usually made retrospectively after animals exhibiting symptoms are slaughtered. The pathogen associated with the disease, $L$. intracellularis, is difficult to culture and no diagnostic reagents, apart from PCR primers (Jones et al., 1993) and a specific $\mathrm{mAb}$ (McOrist et al., 1987) have been developed. Our aim was to use recombinant techniques to produce proteins for use in sero-diagnosis of PE and to identify proteins which may be used for further characterization of this recently identified intracellular bacterium.

At present, co-culture of L. intracellularis is insufficient to allow construction of a representative genomic library. We used bacteria purified from infected ilea of 
pigs to obtain sufficient DNA to construct a partial genomic library. Two seroreactive clones, pISI-1 and pISI-2, were identified when the library was screened with rabbit antisera raised against $L$. intracellularis. Proteins of approximately 10 and $60 \mathrm{kDa}$ were expressed by $E$. coli(pISI-2) as shown by SDS-PAGE and reacted with rabbit (Fig. 1) and pig anti-sera by Western analysis, prompting further analysis of this clone. The $9 \mathrm{~kb}$ insert of E. coli(pISI-1) has not yet been analysed further as seroreactive proteins were not obvious from Western immunoblots of $E$. coli(pISI-1).

Sequence analysis of pISI-2 revealed that it contained an operon encoding homologues of the $E$. coli chaperonins, GroES and GroEL. Molecular chaperones make up a family of proteins which are essential for the folding and correct assembly of mature polypeptides in all types of organisms (Ellis, 1987). Within this family, the chaperonins GroES and GroEL are highly related by sequence and found in all eubacteria, mitochondria and plastids examined (Zeilstra-Ryalls et al., 1991; Ellis, 1992). Homologues of GroES and GroEL, also known as Hsp10 and Hsp60, have been identified from many different organisms, partly attributed to the recent interest in the clinical and biological significance of these proteins.

Given that the library was constructed from material extracted from the ileum of the pig, we established by PCR and sequence analysis that PISI- 2 was derived from L. intracellularis. Unique PCR primers designed from sequences external to the $50 \mathrm{~S}$ ribosomal protein gene cluster on pISI-2 generated PCR amplicons from cocultured L. intracellularis (Collins et al., 1996) and from DNA purified from the ilea of pigs identified with characteristic lesions of PE. The 720 bp PCR amplicon from co-cultured $L$. intracellularis was partially sequenced and was identical to the pISI-2 sequence from which the primers were designed, confirming the origin of the E. coli(pISI-2) clone. PCR amplicons were not generated from DNA extracted from the ilea of pigs showing no symptoms of PE, suggesting the primers may be used to identify $L$. intracellularis-infected pig ilea.

Four ORFs were identified on pISI-2 in addition to the groES/EL operon. The genes for the $50 \mathrm{~S}$ ribosomal proteins L21 and L27 of E. coli form a gene cluster separated from other ribosomal protein genes (Kitakawa et al., 1979). The same gene arrangement has been described for B. subtilis (Dabbs, 1983) and now a similar arrangement is shown in Fig. 3 for L. intracellularis. The sequence downstream of this gene cluster in $L$. intracellularis strongly resembles the sequence of the amino terminus of a GTP-binding protein, Obg, of B. subtilis (Fig. 4). The gene encoding Obg is present in an operon structure with the sporulation gene $s p o 0 B$ and is essential for growth (Kok et al., 1994). The gene for L27 is upstream of the spoOB-obg operon of B. subtilis (Ferrari et al., 1985; Trach \& Hoch, 1989). However, sequence sharing homology with the $s p o 0 B$ gene was not present between the ORFs sharing sequence similarity with $\mathrm{L} 27$ and $\mathrm{Obg}$ in the $L$. intracellularis clone, pISI-2.

An ORF with sequence similarity to a possible protoporphyrinogen oxidase was found downstream of the groES/EL operon within the $L$. intracellularis clone pISI-2. The gene encoding a possible protoporphyrinogen oxidase of $E$. coli, hemK, has been described (Nakayashiki et al., 1995). In the final stages of haem synthesis, protoporphyrinogen is oxidized to protoporphyrin by protoporphyrinogen oxidase. The pathway for haem synthesis involves a number of genes which have been mapped and characterized, and is highly conserved among many different species. In E. coli, hemK forms part of the hemA-prfA-hemK operon involved in the biosynthesis of haem (Nakayashiki et al., 1995). However, little is known of the involvement of bemK in the synthesis of haem.

The size and highly conserved function of GroEL permit its use as a valuable evolutionary chronometer (Viale $e t$ al., 1994). Comparisons of $16 \mathrm{~S}$ rRNA sequences have provided a simple way to classify and relate organisms (Woese, 1987). Based on 16S rRNA phylogenetic studies, L. intracellularis is most closely related to Desulfovibrio desulfuricans (McOrist et al., 1995), sharing 91\% sequence similarity. However, members of this family of sulfate-reducing bacteria belong to the $\delta$ subclass of the Proteobacteria, a subclass in which there are no known intracellular pathogens of vertebrate hosts (Woese, 1987; Devereux et al., 1989). The use of more macromolecules demonstrating features of molecular chronometers, such as GroEL, may help resolve evolutionary relationships between prokaryotes (Woese, 1987; Viale et al., 1994) and place organisms which are difficult to classify, such as L. intracellularis, with more confidence.

Our taxonomic analysis using predicted GroEL amino acid sequences available in the databases revealed very similar genetic relationships to those inferred by the $16 \mathrm{~S}$ rRNA sequence database project. That is, the bacterial species clustered into similar divisions and subdivisions as those defined by the phylogenetic arrangement of $16 \mathrm{~S}$ rRNA sequences and shown in Fig. 7. However, the lack of GroEL sequences from the bacteroides and the $\delta / \varepsilon$ Proteobacteria species in the database means that bootstrap analysis cannot provide enough confidence to assign these affiliations (Viale et al., 1994) which may account for some of the differences between the trees. The phylogenetic tree based on GroEL sequences shows L. intracellularis to be genetically isolated from the other bacteria represented. The closest neighbour to $L$. intracellularis within the incomplete tree is $H$. pylori of the $-\delta / \varepsilon$ subclass of the Proteobacteria, which is consistent with the classification by $16 \mathrm{~S}$ rRNA relationships. Unfortunately, a comparison between Desulfovibrio spp. and L. intracellularis could not be made as there are no GroEL sequences from Desulfovibrio spp. present in the databases. Similarly, GroEL sequences from Campylobacter spp. are not available. Interestingly, the $\mathrm{G}+\mathrm{C}$ content of the $5 \mathrm{~kb}$ insert of $E$. coli(pISI-2) is 34.2 mol\%, which is considerably lower than that of members of the Desulfovibrionaceae. D. desulfuricans 
has a G +C content of $59 \mathrm{~mol} \%$ (Stackebrandt et al., 1995) and few Desulfovibrio spp. have a G $+C$ content of less than $50 \mathrm{~mol} \%$, with none reported having less than $48 \mathrm{~mol} \%$ (Stackebrandt et al., 1995).

With the groE-operon sequence of L. intracellularis now available, it may be possible to identify epitopes specific to L. intracellularis that can be produced by recombinant techniques for diagnostic use. Lally et al. (1995) have demonstrated the use of species-specific GroEL antibodies produced during infection for sero-diagnosis of a disease caused by the intracellular bacterium Cowdria ruminantium, the causative agent of heartwater in ruminants. There have also been a number of reports describing the use of heat-shock proteins as vaccine antigens against intracellular pathogens such as $H$. pylori (Ferrero et al., 1995) and Mycobacterium tuberculosis (Lowrie et al., 1994). Despite their conservation amongst the different kingdoms, heat-shock proteins can activate the immune response following natural infective delivery or when given as vaccines. Hsp65, the GroEL homologue of Mycobacteria, is a prominent antigen of $M$. leprae and $M$. tuberculosis infections. Hsp65 has been used in vaccine trials against Mycobacterium infections and has conferred protective immunity in animal models (Lowrie et al., 1994; Silva \& Lowrie, 1994; Silva et al., 1994). Studies are in progress to determine whether the GroEL homologue from $L$. intracellularis can act as a protective vaccine antigen against porcine PE.

\section{ACKNOWLEDGEMENTS}

We are extremely grateful to Alison Collins for the preparation of co-cultured L. intracellularis and the rat enterocyte cell line and to Meri Sinistaj for her help with the sequence analysis. We also thank A. Viale for the GroEL sequence alignments and for his useful advice. This work was supported by the Pig Research and Development Corporation of Australia.

\section{REFERENCES}

Altschul, S. F., Gish, W., Miller, W., Myers, E. W. \& Lipman, D. J. (1990). Basic local alignment search tool. J Mol Biol 215, 403-410.

Anderson, B. J., Bills, M. M., Egerton, J. R. \& Mattick, J. S. (1984). Cloning and expression in Escherichia coli of the gene encoding the structural subunit of Bacteroides nodosus fimbriae. J Bacteriol 160, 748-754.

Barbosa, M. F., Yomano, L. P. \& Ingram, L. O. (1994). Cloning, sequencing and expression of stress genes from the ethanolproducing bacterium Zymomonas mobilis: the groESL operon. Gene 148, 51-57.

Collins, A. M., Swift, I. \& Monckton, R. P. (1996). Replication of Australian porcine isolates of Ileal symbiont intracellularis in tissue culture. Vet Microbiol 49, 249-255.

Colston, A., McConnell, I. \& Bujdoso, R. (1994). Cloning and expression in Escherichia coli of DNA encoding a $60 \mathrm{kDa}$ stress protein of Mycobacterium paratuberculosis, the causative agent of Johne's disease. Microbiology 140, 3329-3336.

Dabbs, E. R. (1983). A pair of Bacillus subtilis ribosomal protein genes mapping outside the principal ribosomal protein cluster. $J$ Bacteriol 156, 966-969.
Devereux, R., Delaney, M., Widdel, F. \& Stahl, D. A. (1989). Natural relationships among sulfate-reducing bacteria.J Bacteriol 171, 6689-6695.

Duchene, A. M., Kieser, H. M., Hopwood, D. A., Thompson, C. J. \& Mazodier, P. (1994). Characterization of two groEL genes in Streptomyces coelicolor A3(2). Gene 144, 97-101.

Ellis, J. (1987). Proteins as molecular chaperones. Nature 328, 378-379.

Ellis, J. (1992). Cystolic chaperonin confirmed. Nature 358, 191-192.

Ferrari, F. A., Trach, K. \& Hoch, J. A. (1985). Sequence analysis of the $s p o 0 B$ locus reveals a polycistronic transcription unit. $J$ Bacteriol 161, 556-562.

Ferrero, R. L., Thiberge, J.-M., Kansau, I., Wuscher, N., Huerre, M. \& Labigne, A. (1995). The GroES homologue of Helicobacter pylori confers protective immunity against mucosal infection in mice. Proc Natl Acad Sci USA 92, 6499-6503.

Ferreyra, R. G., Soncini, F. C. \& Viale, A. M. (1993). Cloning, characterization and functional expression in Escherichia coli of chaperonin ( $g r o E S L)$ genes from the phototrophic sulfur bacterium Chromatium vinosum. J Bacteriol 175, 1514-1523.

Fox, J. G., Dewhirst, F. E., Fraser, G. J., Paster, B. J., Shames, B. \& Murphy, J. C. (1994). Intracellular Campylobacter-like organism from ferrets and hamsters with proliferative bowel disease is a Desulfovibrio sp. J Clin Microbiol 32, 1229-1237.

Gebhart, C. J., Barns, S. M., McOrist, S., Lin, G.-F. \& Lawson, G. H. K. (1993). Ileal symbiont intracellularis, an obligate intracellular bacterium of porcine intestines showing a relationship to Desulfovibrio species. Int J Syst Bacteriol 43, 533-538.

Gor, D. \& Mayfield, J. E. (1992). Cloning and nucleotide sequence of the Brucella abortus groE operon. Biochim Biophys Acta 1130, 120-122.

Hemmingsen, S. M., Woolford, C., van der Vies, S. M., Tilly, K., Dennis, D. T., Georgopoulos, C. P., Hendrix, R. W. \& Ellis, J. (1988). Homologous plant and bacterial proteins chaperone oligomeric protein assembly. Nature 333, 330-334.

Holyoake, P. K., Cutler, R. S., Caple, W. \& Monckton, R. P. (1994). Enzyme-linked immunosorbent assay for measuring Ileal Symbiont Intracellularis-specific immunoglobulin $G$ response in sera of pigs. J Clin Microbiol 32, 1980-1985.

Jasni, S., McOrist, S. \& Lawson, G. H. K. (1994). Reproduction of proliferative enteritis in hamsters with a pure culture of Ileal Symbiont Intracellularis. Vet Microbiol 41, 1-9.

Jones, G. F., Ward, G. E., Murtaugh, M. P., Lin, G. \& Gebhart, C. J. (1993). Enhanced detection of intracellular organism of swine proliferative enteritis, Ileal Symbiont Intracellularis, in feces by polymerase chain reaction. J Clin Microbiol 31, 2611-2615.

Kim, S. G. \& Batt, C. A. (1993). Cloning and sequencing of the Lactococcus lactis subsp. lactis groESL operon. Gene 127, 121-126.

Kitakawa, M., Dabbs, E. R. \& Isono, K. (1979). Genes coding for ribosomal proteins S15, L21 and L27 map near argG in Escherichia coli. J Bacteriol 138, 832-838.

Kok, J., Trach, K. A. \& Hoch, J. A. (1994). Effects on Bacillus subtilis of a conditional lethal mutation in the essential GTPbinding protein Obg. J Bacteriol 176, 7155-7160.

Laemmli, U. K. (1970). Cleavage of structural proteins during the assembly of the head of bacteriophage T4. Nature 227, 680-685.

Lally, N. C., Nicoll, S., Paxton, E. A., Cary, C. M. \& Sumption, K. J. (1995). The Cowdria ruminantium groE operon. Microbiology 141, 2091-2100. 
Lawson, G. H. K., McOrist, S., Jasni, S. \& Mackie, R. A. (1993). Intracellular bacteria of porcine proliferative enteropathy: cultivation and maintenance in vitro. J Clin Microbiol 31, 1136-1142.

Lindler, L. E. \& Hayes, J. M. (1994). Nucleotide sequence of the Salmonella typhi groEL heat shock gene. Microb Pathog 17, 271-275.

Lowrie, D. B., Tascon, R. E., Colston, M. J. \& Silva, C. L. (1994). Towards a DNA vaccine against tuberculosis. Vaccine 12, 1537-1540.

McOrist, S., Boid, R., Lawson, G. H. K. \& McConnell, I. (1987). Monoclonal antibodies to intracellular Campylobacter-like organisms of the porcine proliferative enteropathies. Vet $\operatorname{Rec} 121$, $421-422$.

McOrist, S., Lawson, G. H. K., Roy, D. J. \& Boid, R. (1990). DNA analysis of intracellular campylobacter-like organisms associated with the porcine proliferative enteropathies: novel organism proposed. FEMS Microbiol Lett 69, 189-194.

McOrist, S., Jasni, S., Mackie, R. A., Macintyre, N., Neef, N. \& Lawson, G. H. K. (1993). Reproduction of porcine proliferative enteropathy with pure cultures of Ileal Symbiont Intracellularis. Infect Immun 61, 4286-4292.

McOrist, S., Mackie, R. A., Neef, N., Aitken, I. \& Lawson, G. H. K. (1994). Synergism of Ileal Symbiont Intracellularis and gut bacteria in the reproduction of porcine proliferative enteropathy. Vet Rec 134, 331-332.

McOrist, S., Gebhart, C. J., Boid, R. \& Barns, S. M. (1995). Characterisation of Lawsonia intracellularis gen. nov., sp. nov., the obligately intracellular bacterium of porcine proliferative enteropathy. Int J Syst Bacteriol 45, 820-825.

Maeda, H., Miyamoto, M., Hongyou, H., Kitanaka, M., Nagai, A., Kurihara, H. \& Murayama, Y. (1994). Heat shock protein 60 (GroEL) from Porphyromonas gingivalis: molecular cloning and sequence analysis of its gene and purification of the recombinant protein. FEMS Microbiol Lett 119, 129-135.

Moses, E. K., Rood, J. I., Yong, W. K. \& Riffkin, G. G. (1989). Molecular analysis of one of multiple protease-encoding genes from the prototype virulent strain of Bacteroides nodosus. Gene 77, 219-228.

Nakayashiki, T., Nishimura, K. \& Inokuchi, H. (1995). Cloning and sequencing of a previously unidentified gene that is involved in the biosynthesis of heme in Escherichia coli. Gene 153, 67-70.

Ohta, T., Honda, K., Kuroda, M., Saito, K. \& Hayashi, H. (1993). Molecular characterization of the gene operon of heat shock proteins Hsp60 and Hsp10 in methicillin-resistant Staphylococcus aureus. Biochem Biophys Res Commun 193, 730-737.

Pannekoek, Y., Dankert, J. \& van Putten, J. P. (1995). Construction of recombinant neisserial Hsp60 proteins and mapping of antigenic domains. Mol Microbiol 15, 277-285.

Rasunganwa, E. \& Gupta, R. S. (1993). Cloning and characterisation of multiple groEL chaperonin-encoding genes in Rhizobium meliloti. Gene 126, 67-75.

Rowland, A. C. \& Lawson, G. H. K. (1974). Intestinal adenomatosis in the pig: immunofluorescent and electron microscope studies. Res Vet Sci 17, 323-330.

Sambrook, J., Fritsch, E. F. \& Maniatis, T. (1989). Molecular Cloning: a Laboratory Manual, 2nd edn. Cold Spring Harbor, NY: Cold Spring Harbor Laboratory.

Segal, G. \& Ron, E. Z. (1993). Heat shock transcription of the groESL operon of Agrobacterium tumefaciens may involve a hairpin-loop structure. J Bacteriol 175, 3083-3088.

Silva, C. L. \& Lowrie, D. B. (1994). A single mycobacterial protein (Hsp65) expressed by a transgenic antigen-presenting cell vaccinates mice against tuberculosis. Immunology 82, 244-248.

Silva, C. L., Silva, M. F., Pietro, R. C. L. R. \& Lowrie, D. B. (1994). Protection against tuberculosis by passive transfer with $T$-cell clones recognizing mycobacterial heat-shock protein 65 . Immunology 83, 341-346.

Stackebrandt, E., Stahl, D. A. \& Devereux, R. (1995). Taxonomic relationships. In Sulfate-reducing Bacteria, pp. 49-87. Edited by L. L. Barton. New York: Plenum Press.

Thole, J. E. R., Keulen, W. J., Kolk, A. H. J., Groothuis, D. G., Berwald, L. G., Tiesjema, R. H. \& van Embden, J. D. A. (1987). Characterization, sequence determination and immunogenicity of a 64-kilodalton protein of Mycobacterium bovis BCG expressed in Escherichia coli K-12. Infect Immun 55, 1466-1475.

Thompson, J. D., Higgins, D. G. \& Gibson, T. J. (1994). CLUSTAL w : improving the sensitivity of progressive multiple sequence alignment through sequence weighting, position-specific gap penalties and weight matrix choice. Nucleic Acids Res 22, 4673-4680.

Towbin, H., Staehelin, T. \& Gordon, J. (1979). Electrophoretic transfer of proteins from polyacrylamide gels to nitrocellulose sheets : procedure and some applications. Proc Natl Acad Sci USA 76, 4350-4354.

Trach, K. \& Hoch, J. A. (1989). The Bacillus subtilis spoOB stage 0 sporulation operon encodes an essential GTP-binding protein. $J$ Bacteriol 171, 1362-1371.

Viale, A. M., Arakaki, A. K., Soncini, F. C. \& Ferreyra, R. G. (1994), Evolutionary relationships among eubacterial groups as inferred from GroEL (chaperonin) sequence comparisons. Int J Syst Bacteriol 44, 527-533.

Wallington, E. J. \& Lund, P. A. (1994). R hizobium leguminosarum contains multiple chaperonin (cpn60) genes. Microbiology 140, 113-122.

Welsh, K. M., Trach, K. A., Folger, C. \& Hoch, J. A. (1994). Biochemical characterisation of the essential GTP-binding protein Obg of Bacillus subtilis. J Bacteriol 176, 7161-7168.

Woese, C. R. (1987). Bacterial evolution. Microbiol Rev 51, 221-271.

Zeilstra-Ryalls, J., Fayet, O. \& Georgopoulos, C. (1991). The universally conserved GroE (Hsp60) chaperonins. Annu Rev Microbiol 45, 301-325.

Received 16 December 1997; accepted 31 March 1998. 